\title{
PROGRAMAS E POLÍTICAS DE FORMAÇÃO CONTINUADA DE GESTORES ESCOLARES DO ESTADO DE SÃO PAULO EM ANÁLISE
}

Andréia Nunes Militão

Doutoranda em Educação - PPGE - FCT/UNESP. Email: andreianmilitao@terra.com.br. Agência de Fomento: FAPESP

\section{RESUMO}

Este trabalho discute os programas e políticas de formação de gestores escolares (diretores, vicediretores, coordenadores pedagógicos) que vem sendo implementados pela Secretaria Estadual de Educação do Estado de São Paulo (SEE/SP), durante o governo de Geraldo Alckmin (PSDB). A abordagem metodológica, de natureza qualitativa, recorre à literatura produzida na área e à pesquisa documental. Depreende-se, que embora tenha se ampliado o foco sobre o caráter pedagógico da gestão escolar, há indícios que apontam para um processo de responsabilização dos diretores pelos resultados pedagógicos. Para responder à sociedade, a tônica das políticas públicas educacionais tem intensificado os processos formativos dos gestores. Concluí-se que o grande volume de cursos direcionados aos gestores editados pelo governo paulista coloca a gestão num lugar reverencial, sendo tratada como a solução para todos os males da educação.

Palavras-chave: Políticas Públicas. Gestão Escolar. Dimensão Pedagógica. Formação dos Gestores Escolares. Governo Estadual Paulista.

\section{INTRODUÇÃO E OBJETIVO}

O presente trabalho objetiva apresentar e discutir os programas e as políticas de formação destinadas aos gestores escolares que vem sendo implementadas nas escolas públicas do Estado de São Paulo, detendo-se na análise das políticas de formação dos gestores durante o governo de Geraldo Alckmin (PSDB), ainda em curso.

Nossa hipótese é que o atual governo vem colocando em ação, de forma concomitante, diferentes programas com foco na formação dos gestores escolares (diretor, vice-diretor, coordenador pedagógico), de forma a responsabilizá-los pelos resultados das avaliações externas. Neste sentido, essas ações somam-se às tradicionais políticas de formação docente, centrando nos trabalhadores as responsabilidades ou "peso" pela melhoria da qualidade da educação.

Garcia caracteriza como "projetismo" a prática da "utilização intensiva de propaganda e do marketing [que] provoca o deslocamento do eixo da política educativa para ações e programas que possam trazer visibilidade imediata". Nesse sentido, é difícil, numa primeira análise, captar o sentido dos projetos e programas que se multiplicam em quantidade e variedade. $O$ autor continua, caracterizando a "gestão educacional pelas interrupções e não pela cumulatividade. A continuidade se dá por descontinuidade e interrupções" (GARCIA, 2009, p. 115). 


\section{METODOLOGIA}

Com o intuito de identificar o conceito de gestão escolar que embasa a legislação do Estado de São Paulo, optamos pelo uso da pesquisa documental. Assim, para a realização do estudo sobre a gestão escolar e suas interfaces com o desenvolvimento profissional docente buscamos as orientações que emanam dos documentos produzidos pelo próprio sistema de ensino do Estado de São Paulo.

Ao recorrermos à pesquisa documental não podemos deixar de considerar o contexto de produção dos mesmos, ou seja, entendemos que estes "Não são apenas uma fonte de informação contextualizada, mas surgem num determinado contexto e fornecem informações sobre esse mesmo contexto" (LUDKE, ANDRÉ, 1986, p.39). Também é preciso romper com a ideia de que os documentos contêm a "verdade".

$\mathrm{Na}$ perspectiva adotada nessa investigação, consideramos que os documentos representam uma visão sobre os fatos/acontecimentos e que não podem prescindir da análise de outras visões e de outros tipos de fontes. Nesta etapa estamos nos debruçando mais detidamente nos documentos produzidos pelo governo paulista no âmbito da SEE/SP.

A coleta de documentos ocorreu por meio de pesquisa à página eletrônica da Secretaria Estadual de Educação (SEE), pois de acordo com informações obtidas na Diretoria de Ensino de Presidente Prudente/SP, estão disponibilizados no ambiente digital todos os documentos (decretos, resoluções e normatizações legais) produzidos pelo governo do Estado de São Paulo. Em levantamento inicial realizado por meio de documentos e informativos da própria SEE/SP buscamos informações sobre os projetos, programas e orientações que embasam a formação dos gestores escolares.

\section{RESULTADOS}

A partir do lançamento do programa de governo denominado "Educação - compromisso de São Paulo", em 2011, houve uma intensificação sobre o trabalho dos gestores escolares bem como sobre sua formação. O referido programa se configura como um "guarda-chuva" que abarca todas as ações do governo para a melhoria do ensino. No nosso entendimento, explicita mais uma marca de governo do que propriamente um conjunto de ações articuladas sob uma mesma fundamentação.

Em que pese à importância da formação continuada de todos os profissionais da educação, os termos adotados para esse programa não parecem corresponder à continuidade de práticas de 
formação, reforçando o que afirmou Garcia (2009), a apresentação do programa se assemelha mais a uma "peça de marketing" do que a uma descrição da importância da formação como algo permanente.

A ação inédita da Secretaria da Educação "Melhor Gestão, Melhor Ensino" faz parte do programa Educação - Compromisso de São Paulo. O objetivo é envolver cerca de 65 mil educadores da rede estadual paulista dos anos finais - 60 ao 9o ano - do Ensino Fundamental em uma série de ações voltadas para o aprimoramento das competências que beneficiará cerca de 1,7 milhão de alunos. A iniciativa receberá um investimento de quase $\mathrm{R} \$$ 30 milhões (SÃO PAULO, 2013).

Cabe ressaltar que, quando anunciado o programa de governo "Educação-compromisso de São Paulo", uma da metas propostas era colocar a educação do estado entre "as mais avançadas do mundo até 2030 , com base nos dados mais recentes divulgados pelo Pisa, sigla em inglês para o Programa Internacional de Avaliação de Alunos". Portanto, as últimas medidas educacionais tomadas pelo governador estão diretamente aportadas nessa perspectiva.

Denota-se que "o uso do marketing como forma de convencer desloca o eixo do debate do mérito intrínseco das proposições para a melhor técnica de convencimento do grande público" (GARCIA, 2009, p. 115). Assim, não têm sido incomuns a publicização das medidas adotadas pelo atual governo. Essa postura revela, como observado pelo autor, a preocupação por parte do atual governo paulista de "incutir no grande público a convicção que essas providências são responsáveis pela melhoria da qualidade de ensino".

Para corroborar nosso entendimento sobre a atual política de formação da SEE/SP, expomos a seguir alguns dos documentos elaborados para a formação de gestores e professores nos últimos anos. A consulta inicial ao site da SEE/SP sinaliza para a mudança em torno das políticas de formação, que amplia o foco para a formação continuada de professores para priorizar a formação dos gestores.

\section{DISCUSSÃO}

Ao analisarmos os programas de formação de gestores e de professores do Estado de São Paulo, torna-se importante destacar que a Escola de Formação e Aperfeiçoamento dos Professores do Estado de São Paulo "Paulo Renato Costa Souza" (EFAP) ${ }^{1}$, responsável pela formação

\footnotetext{
${ }^{1}$ Decreto no 56.460, de 30 de novembro de 2010 Aprova o Regimento Interno da Escola de Formação e Aperfeiçoamento dos Professores do Estado de São Paulo - EFAP, criada pelo Decreto no 54.297, de 5 de maio de 2009, em substituição à CENP e organizada pelo Decreto no 55.717 , de 19 de abril de 2009, e dá providências correlatas.
} 
continuada, mantém diversas parcerias com instituições públicas e privadas. De acordo com texto do site são "dedicadas ao fomento à educação". Como exemplos dessas parcerias são indicadas: "USP, UNICAMP, UNESP, Universidade Anhembi Morumbi, Fundação Lemann, Instituto Crescer, British Council, Corpo de Bombeiros, Microsoft, Intel e Comgás".

A EFAP mantém o site "Rede do Saber" onde traz a relação dos cursos de formação que oferece. Dentre os cursos em funcionamento localizamos o MBA Gestão Empreendedora Educação que já se encontra na terceira edição. Novamente destaca-se que a ênfase dada pelo curso é:

A intenção é promover ações de formação continuada aos gestores, garantindo o desenvolvimento de uma visão estratégica, com aquisição de competências gerenciais e habilidades de liderança que possibilitem uma atuação bem-sucedida, alavancando os resultados do rendimento dos alunos matriculados na rede de escolas públicas do Estado de São Paulo, conforme a atual política educacional que atua com programas, projetos e ações focados na análise e na utilização de resultados.

Observa-se que embora haja uma profusão de cursos com diferentes nomenclaturas, a concepção presente nos mesmos centram-se em "obter os melhores resultados na gestão de uma escola, universidade ou rede de ensino", conforme explicitado nos objetivos do curso Master em Gestão Escolar.

O curso é presencial, tem duração de 3 semestres e, apesar de ter como referência sólida base teórica, dá ênfase aos aspectos práticos e atuais da gestão de escolas e secretarias de educação. Disciplinas como Educação à Distância e Novas Tecnologias, Gestão Estratégica e Ferramentas Estatísticas para Gestão Educacional compõem o currículo.

Outro curso elencado pela SEE/SP, oferecido na modalidade de pós-graduação lato sensu com total de 390 horas, sendo a maior parte organizada em ambiente virtual e com seis encontros presenciais é o Gestão para o Sucesso Escolar, promovido pela Escola de Formação de Professores e da Coordenadoria de Estudos e Normas Pedagógicas (CENP) e Coordenadoria de Ensino da Região Metropolitana da Grande São Paulo (COGSP). Embora seja acompanhado pela Fundação Lemann, o curso foi elaborado e certificado pela Universidade Anhembi-Morumbi, explicitando uma simbiose entre universidade privadas e órgãos internacionais.

O GSE tem como objetivo transformar o gestor em um disseminador de conhecimentos e um agente na formação de equipes cooperativas nas escolas, cujas lideranças deverão estimular: a mudança como componente orgânico da vida escolar; o acompanhamento permanente dos processos 
de tomada de decisão; o estabelecimento de acordos entre os diferentes atores do processo educacional.

Como critério para participação no curso foi colocado que o mesmo é destinado para diretores em exercício em escolas que tenham o Ciclo I do Ensino Fundamental e que sejam pertencentes à Coordenadoria de Ensino da Região Metropolitana da Grande São Paulo (COGSP).

Também localizamos no site informações sobre o Programa de Capacitação a Distância para Gestores Escolares (PROGESTÃO), ofertado em parceria entre secretarias estaduais e municipais de educação e o CONSED e "já contou com apoio e cooperação da Fundação FORD, da Universidad Nacional de Educación a Distancia - UNED e da Fundação Roberto Marinho". De acordo com o texto do site, destina-se a "capacitação de lideranças escolares".

Foi desenhado a partir de uma demanda específica de um grupo de Secretários de Estados da Educação, no final da década de 90, tendo como meta principal o desenvolvimento de uma gestão democrática focado no sucesso escolar do aluno.

Denota-se, dessa forma, que a SEE/SP tem privilegiado a formação dos gestores escolares, utilizando-se para tanto de vários instrumentos: cursos de pós-graduação em parceria com universidades públicas e privadas, videoconferências, reuniões de capacitação nas Diretorias de Ensino e elaboração de materiais específicos para os gestores, sendo o maior exemplo os Cadernos dos Gestores.

A pesquisa documental indicou ainda que a gestão escolar na atualidade tem sido norteada a partir de dois programas: Plano de Ação Participativo para Escolas (PAP), parte integrante do Programa Educação - Compromisso de São Paulo e do Prêmio Gestão Escolar (PGE), organizado pelo CONSED em parceria com as SEE's de diversos estados. O tutorial do PAP destaca que a SEE/SP vem realizando ações com o objetivo de propagar "novos modelos de gestão escolar". Destaca, dessa forma, como exemplos:

São exemplos o Progestão; os Planos de Gestão e Ação quadrienais elaborados pelas Diretorias de Ensino e pelas Escolas; e os Grupos de Referência, que promovem um processo descentralizado e sistemático de orientação técnica e de acompanhamento a professores e gestores. Tratase de uma proposta fundamentada na formação e na prática profissional de cada um dos integrantes, na construção de uma cultura de análise de práticas gestoras a partir da integração, participação, colaboração, cooperação, pautada num processo reflexivo dialógico, com foco na aprendizagem do aluno (PAP, 2012, p. 5). 
Verifica-se, dessa forma, a existência de deslocamento da centralidade da formação continuada de professores para a formação continuada de gestores, reforçada pelo documento do PAP (2012), conforme explicitado no fragmento:

A melhoria da qualidade do ensino e do desempenho dos alunos tem sido o foco central dessas iniciativas, as quais têm como alvo a atuação dos gestores (Diretores, Vice-Diretores, Supervisores de Ensino e Dirigentes Regionais) e das equipes escolares. Em seu conjunto, essas iniciativas procuram disseminar uma nova cultura de gestão, democrática, participativa e orientada ao alcance de resultados (PAP, 2012, p. 5).

O documento aponta para a existência de cinco dimensões da gestão escolar: gestão pedagógica, gestão dos recursos humanos, gestão participativa, gestão dos recursos físicos e financeiros e gestão de resultados educacionais do ensino e da aprendizagem.

Mesmo anteriormente à esse processo de reestruturação institucional, a SEE já apontava para mudanças sobre como definia e o que esperava de seus profissionais. A análise da Resolução SE 70, de 26-10-2010, normatiza o perfil desejado para os profissionais da educação desde professores até gestores, indicando quais competências e habilidades são requeridas para o provimento dos cargos.

A resolução destaca que o trabalho do diretor deve ser realizado em parceria com o supervisor de ensino. Dentre as atribuições gerais para os diretores escolares, destaca que este deve "[...] em sua esfera de competência, garantir, a concretização da função social da escola, liderando o processo de construção de identidade de sua instituição, por meio de uma eficiente gestão, nas seguintes dimensões: de resultados educacionais do ensino e da aprendizagem; participativa; pedagógica; dos recursos humanos; dos recursos físicos e financeiros". A atribuição específica do diretor de escola, de acordo com este documento, está dividida em: área de resultados educacionais, área de planejamento e gestão democrática; área pedagógica; área de gestão de pessoas e área de gestão de serviços e recursos.

Embora o referido documento explicite outras áreas destinadas à atuação dos gestores, tais como planejamento e gestão democrática, pedagógica, 'gestão de pessoas' e a área de gestão de serviços e recursos, verificamos que o foco da ação formativa tem sido, sobretudo, na dimensão dos resultados pedagógicos, com foco nas repercussões do processo educativo diante das avaliações externas. Nesta perspectiva, o documento supracitado indica como competência geral necessárias aos diretores de escola "compreender a visão contemporânea de gestão escolar vinculada a resultados" e "compreender os sistemas e processos de avaliações externas". 
Por fim, temos o mais recente programa de formação da Secretaria Estadual de Educação de São Paulo (SEE/SP), intitulado "Programa Melhor Gestão, Melhor Aprendizagem"², que traz como objetivo melhorar o desempenho dos alunos nas avaliações externas, dando ênfase ao ensino de matemática e português.

O programa, oferecido por meio da Escola de Formação e Aperfeiçoamento dos Professores do Estado de São Paulo "Paulo Renato Costa Souza" (EFAP) e da Coordenadoria de Gestão da Educação Básica (CGEB), tem foco na gestão escolar e no processo de ensino e de aprendizagem de língua portuguesa e de matemática. $O$ intuito é melhorar o desempenho dos alunos dos anos finais do Ensino Fundamental nessas duas áreas do conhecimento, que são a base para a aprendizagem das demais disciplinas (SÃO PAULO, 2011).

No entanto, ao analisarmos o formato desse curso, verificamos que o referido programa carrega limitações, pois se constitui em mais um curso ofertado na modalidade semipresencial, com carga horária reduzida de $60 \mathrm{hs}$, somado ao fato de não estar clara qual a diferença que apresenta em relação aos outros cursos e programas implementados pela própria SEE/SP nos últimos anos.

Em relação a efetivação da demanda de formação, os informativos da EFAP demonstram que a ênfase se dá por meio de cursos em ambientes virtuais, videoconferências e encontros presencias. Também elabora os cursos que passaram a ser uma exigência para o ingresso por concurso público, o que no nosso entender visa doutrinar os futuros profissionais à lógica da gestão e do ensino voltados para resultados.

Não obstante a literatura especializada aponte que "não basta alterar as regras formais para mudar as realidades escolares, e estas mudam, com freqüência mesmo quando as primeiras se mantêm inalteradas" (LIMA, 2002, p. 51), pelo exposto, no caso do estado de São Paulo as constantes edições de novos projetos destinados à formação de gestores e professores têm se traduzido em velhas práticas.

Talvez por isso não tenham a adesão dos sujeitos que se encontram no "chão da escola". Na perspectiva de Lima (2002, p. 51), "não são apenas os modelos decretados que influenciam as práticas de gestão; essas práticas são influenciadas por múltiplos factores, objectivos, interesses, circunstâncias, etc., que, por sua vez, não deixam de influenciar o entendimento e até a produção dos modelos decretados".

\footnotetext{
${ }^{2}$ Informações disponíveis em: http://www.educacao.sp.gov.br/portal/projetos/compromisso-sp
} 


\section{CONCLUSÕES}

Os documentos avaliados até o presente momento nos levam a concluir que "a gestão emerge fundamentalmente como uma terapia que permite resolver as questões anómalas verificadas ao nível do funcionamento da organização, por adopção, através por exemplo do contágio institucional, das estruturas que se institucionalizam na sociedade (empresarial) como conducentes à qualidade ou à excelência" (ESTEVÂO, 2002, p. 84).

Dessa forma, o grande volume de cursos direcionados aos gestores editados pelo governo paulista colocam a gestão num lugar reverencial, sendo tratada como a solução para todos os males da educação.

Se durante as décadas de 1980 e 1990 se responsabilizava os docentes pelas mazelas educacionais e como solução para todos os problemas educacionais, receitando-se cursos de "treinamento" e "capacitação". Agora, tornou-se lugar comum atribuí-las aos gestores escolares, o que, por um lado, retira a responsabilidade da gestão educacional em debater as políticas públicas educacionais de forma mais ampla, por outro, coloca a gestão localizada apenas no âmbito da escola, anunciada com um papel redentor, como tem sido recorrente no estado de São Paulo.

\section{REFERENCIAS}

CONSED. Prêmio Gestão Escolar 2012 - Manual de Orientações. Disponível em <http://www.consed.org.br/index.php/progestao>. Acesso em 18 jan. 2013.

GARCIA, W. Tecnocratas, educadores e os dilemas da gestão. In: FERREIRA, N. S. C.; AGUIAR, M. A. da S.(org.). Gestão da educação: impasses, perspectivas e compromissos. 7. ed. São Paulo: Cortez, 2009.

LIMA, L. Modelos organizacionais de escola: perspectivas analíticas, teorias administrativas e o estudo da aç̧ão. In: MACHADO, L. M.; FERREIRA, N. S. C. (orgs.). Políticas e gestão da educação: dois olhares. Rio de Janeiro: DP\&A, 2002.

LÜDKE, M.; ANDRÉ, M. E. D. A. Pesquisa em educação: abordagens qualitativas. São Paulo: EPU, 1986.

SÃO PAULO. (Estado). Secretaria da Educação do Estado de São Paulo. Decreto no 55.717, de 19 de abril de 2010a. Organiza a Escola de Formação e Aperfeiçoamento dos Professores do Estado de São Paulo e dá providências correlatas. São Paulo: Diário Oficial do Estado de São Paulo, 20/04/2010, p.04, Seção 1.

SÃO PAULO. (Estado). Secretaria da Educação do Estado de São Paulo. Resolução SE no 70 de 26 de outubro de 2010b. Dispõe sobre os perfis profissionais, competências e habilidades requeridos dos educadores da rede pública estadual e os referenciais bibliográficos que fundamentam os 
exames, concursos e processos seletivos, e dá providências correlatas. São Paulo: Diário Oficial do Estado de São Paulo, 27/10/2010, p.26-27, Seção 1.

SÃO PAULO. (Estado). Educação lança "Melhor Gestão, Melhor Ensino", com foco em 65 mil docentes da rede. Disponível em <http://www.educacao.sp.gov.br/noticias/educacao-investe-r30-milhoes-em-programa-voltado-para-65-mil-educadores-da-rede-estadual>. Acesso em 30 jan. 2013a.

SÃO PAULO. (Estado). Secretaria da Educação do Estado de São Paulo. Tutorial do Plano de Ação Participativo para Escolas. 2012. Guia Para Elaboração, 1 v. Disponível em: <http://www.saopaulo.sp.gov.br/acoesdegoverno/educacao/\# compromisso-de-sao-paulo>. Acesso em: 13 fev. 2013b.

SÃO PAULO. (Estado). MBA Gestão Empreendedora. Disponível em: <http://www.rededosaber.sp.gov.br/portais/Not\%C3\%ADciasConte\%C3\%BAdo/tabid/369/languag e/pt-BR//IDNoticia/1401/Default.aspx>. Acesso em: 15 fev. 2013c.

SÃO PAULO. (Estado). Gestão para o Sucesso Escolar. Disponível em: <http://www.rededosaber.sp.gov.br/portais/Portals/53/arquivos/Regulamento_gestao_suc_escol ar_atualizado_09_03.PDF>. Acesso em: $15 \mathrm{fev} .2013 \mathrm{~d}$. 